\title{
The Effect of Engineering Education Accreditation on Materials Engineering Education in University of Seoul
}

\section{Hakjin Kim $^{\mathrm{a}}$ and Ohsung Song ${ }^{\mathrm{b}}$}

${ }^{a}$ Innovation Center for Engineering Education, ${ }^{b}$ Department of Materials Science and Engineering, University of Seoul, Republic of Korea.

\begin{abstract}
Korea implemented the Engineering Education Accreditation system in 2001, and it was adopted by 85 engineering colleges (out of 165) in 2015. Focusing on the Department of Materials Engineering at the University of Seoul, this study performed a time-series analysis of Grade Point Average (GPA), employment rate, and credits earned in Mathematics, Science, Computer $(M S C) / d e s i g n / m a j o r$ courses to compare the differences in academic achievements between accredited and non-accredited graduates. The results showed that accredited graduates had a generally higher GPA and employment rate than non-accredited students, and this can be traced to the curricula provided under the accreditation system having a positive effect on improving communication, teamwork, and creativity.
\end{abstract}

Keywords: Engineering Education Accreditation; Materials Engineering; Engineering Education 


\section{Introduction}

The Accreditation Board for Engineering Education of Korea (ABEEK) has performed accreditation every year for engineering education, beginning with two universities in 2001 . According to the annual report of 2015, 549 programs in 85 out of 165 engineering colleges received accreditation as Engineering Accreditation Commission (EAC) or Computing Accreditation Commission (CAC). By major, the 549 accredited programs include 114 in electrical engineering, 85 in mechanical engineering, 51 in civil engineering, 51 in chemical engineering, 44 in architectural engineering, and 41 in materials engineering. These six engineering majors make up about $70 \%$ of all programs, and the field of materials engineering accounts for a significant $7.5 \%$.

Despite the increase in the number of accredited engineering programs and accredited graduates, the accreditation system has received criticism. Some universities have not participated or are choosing to abolish accreditation, and the effectiveness of the accreditation system is under question. The reasons include the constraint on autonomous operation, the 2-3 year frequency of evaluations, lack of professional evaluators, increased burden on faculty, and lack of benefits for graduates of accredited programs (Cho, 2012). Students' feedback on accredited programs indicates that the fulfillment of program credits leaves them with fewer options for other courses, and that they do not benefit much from mandatory, intensive activities such as team projects and preparation of design reports.

With the government enforcing Engineering Education Accreditation and announcing related policies, it is essential to perform a comprehensive evaluation of the effectiveness of the accreditation system in enhancing the competencies of students. The microscopic effects of accreditation should be assessed from the perspective of departments implementing such programs. The basic goal of the accreditation system, that is, to foster talent in engineering and technology to meet the demands of industries and society, must also be reviewed.

Against this backdrop, this study analyzed the effects of Engineering Education Accreditation based on GPA and employment rate of accredited and non-accredited graduates of the Department of Materials Engineering at the University of Seoul, which has implemented the accredited system for ten years. 


\section{Theoretical Background}

The Engineering Education Accreditation system is not mandatory, and universities can choose to adopt the system or not. Engineering education programs satisfying accreditation criteria are granted accreditation status, and are encouraged to continue innovative efforts to improve program quality. An engineering program seeking to earn accreditation status must be operated by a four-year university that offers a bachelor's of engineering, and satisfy criteria such as educational objectives, learning outcomes, curriculum, and CQI. In addition, the program should be designed to be demand-oriented and performance-centered. Under ABEEK guidelines, materials engineering majors of accredited programs must fulfill a requirement of at least $30 \mathrm{MSC}$ credits and 9 design course credits.

The Engineering Education Accreditation system was first implemented in 2001, and its effectiveness and achievements have not been widely studied. Recently, research has focused on the effects of the Engineering Education Accreditation system (Kang, 2012), performance of accredited programs (Park, 2015), effect of accreditation on graduate employment rates in the same field as their majors (Kim, 2014), difference in employments rate between accredited and non-accredited graduates (Jeon, 2013), the effects of accreditation on curriculum in engineering education (Cho, 2012), and the relationship between engineering students' course grades and Korea Collegiate Essential Skills Assessment (K-CESA) core competencies. While these studies are meaningful in examining general performance or trends of the accreditation system for a specific sample of graduates based on survey responses by graduates, faculty and industry personnel, they have been inadequate in providing an analysis of microscopic performance or performance over time at the program level, which is the basic operating unit of the accreditation system. As such, this study seeks to analyze the effects of the accreditation system on a specific department (Department of Materials Engineering). 


\section{Method of Analysis}

First, in determining the number of four-year universities offering a materials engineering major and the accreditation status of materials engineering programs, this study integrated Semiconductor, Ceramics, Materials, Advanced Materials, and Metallurgical Engineering departments under the broad field of materials engineering based on data provided by the Engineering Education Information Center (http://www.eeic.or.kr) and ABEEK (http://www.abeek.or.kr).

Second, to assess the effects of Engineering Education Accreditation on department education, this study conducted a time-series analysis of the achievements of accredited and non-accredited graduates from the Department of Materials Engineering at the University of Seoul. The analysis, focusing on accredited and non-accredited graduates from 2009 to 2014, covered differences in GPA, employment rate, MSC, design courses, and major courses.

\section{Results}

4.1. Statistics on Materials Engineering Graduates of Four-year Universities and Graduates of Accredited Programs in Korea

Figure 1 shows the number of graduates produced from accredited materials engineering programs of ABEEK from 2010 to 2014. The number of graduates grew more than twofold in four years, from 436 in 2010 to 1,101 in 2014. These accredited graduates account for about $24 \%$ of the total number of materials engineering graduates of four-year universities, which amount to approximately 4,500 .

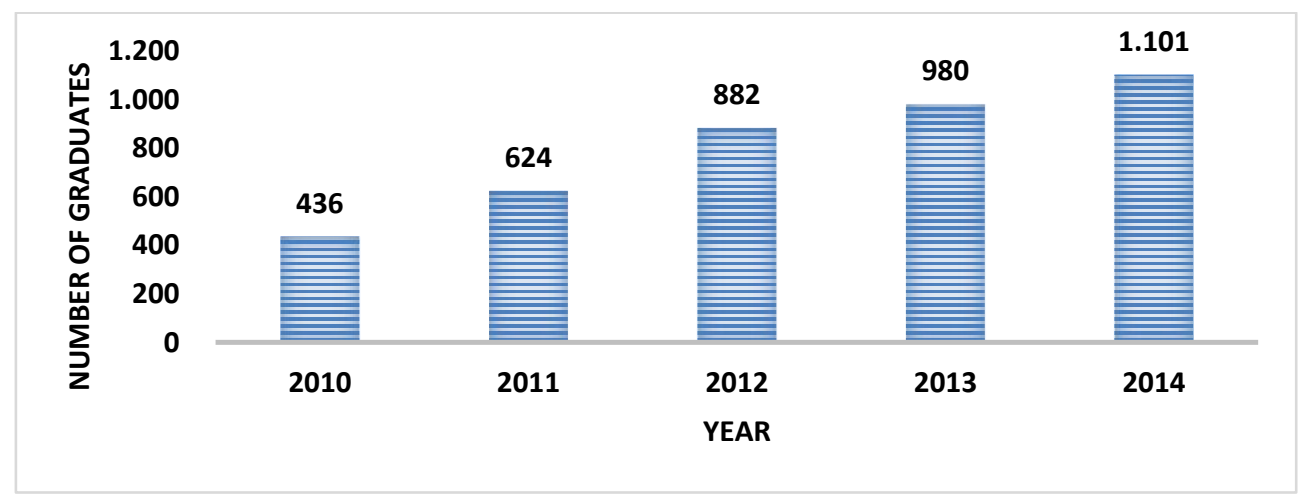

Figure 1. Number of graduates produced from accredited materials engineering programs. 


\subsection{Comparison of Academic Performance of Accredited and Non-accredited Graduates} of the Department of Materials Engineering at the University of Seoul

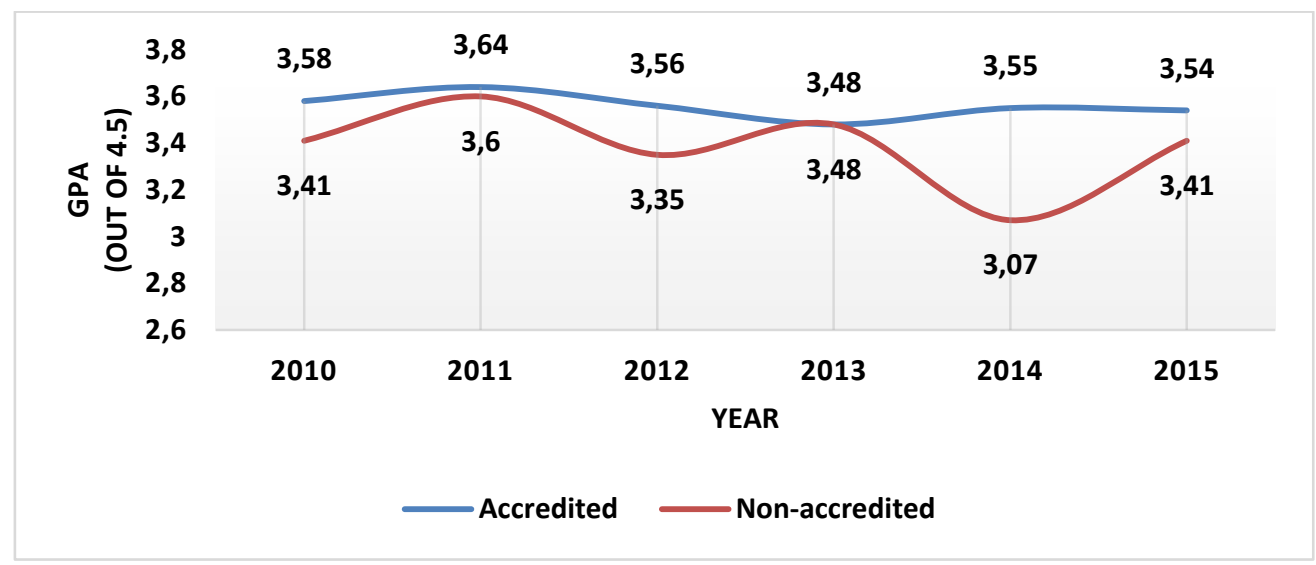

Figure 2. Comparison of GPA between accredited and non-accredited graduates by year.

Figure 2 shows the GPA of accredited and non-accredited graduates by year. Accredited graduates had a slightly higher GPA than non-accredited graduates in all years except for 2013, when the two groups performed similarly. The difference was most prominent at 0.48 in 2014. The reason for the similar performance in 2013 between the two groups is the small number of non-accredited graduates in that year (only 5 out of 32 were nonaccredited). As such, the difference of GPA in 2013 between accredited and non-accredited graduates cannot be considered significant.

Figure 3 shows the employment rate of accredited and non-accredited graduates by year. The employment rate of accredited graduates was higher by a minimum of $5 \%$ and a maximum of $67 \%$ through the research period (2009-2016), indicating that the intensive new materials engineering program at the University of Seoul has boosted employment among graduates. This is consistent with the results reported by Kim et al. In 2013, the employment rate of accredited and non-accredited graduates was $85.2 \%$ and $80.0 \%$, respectively. The small difference compared to other years can be traced to the small number of non-accredited graduates in 2013, and their similar GPA to that of accredited graduates. 


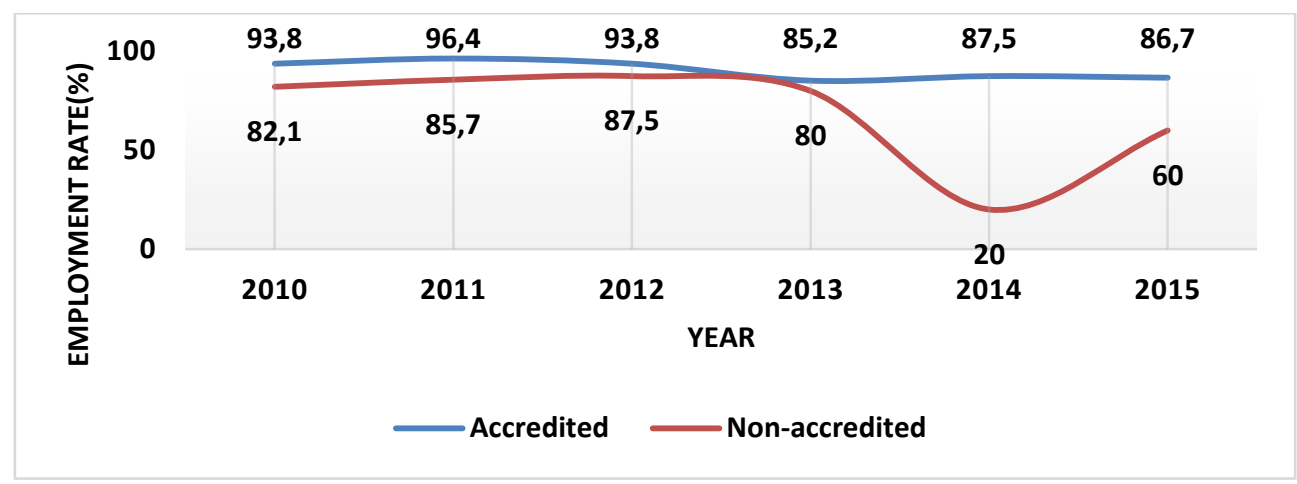

Figure 3. Comparison of employment rate between accredited and non-accredited graduates by year.

Figure 4 shows the fulfillment of MSC credits between accredited and non-accredited graduates by year. Accredited graduates completed 2.5 credits to 14.4 credits more in MSC courses than non-accredited graduates. Accredited graduates completed about $30 \mathrm{MSC}$ credits each year, which is the minimum requirement for graduation. On the other hand, non-accredited graduates earned fewer credits since courses such as Engineering Mathematics 1 and 2 were not mandatory. This is presumed to be related to the gradual decline in employment of non-accredited graduates, as shown in Figure 3.

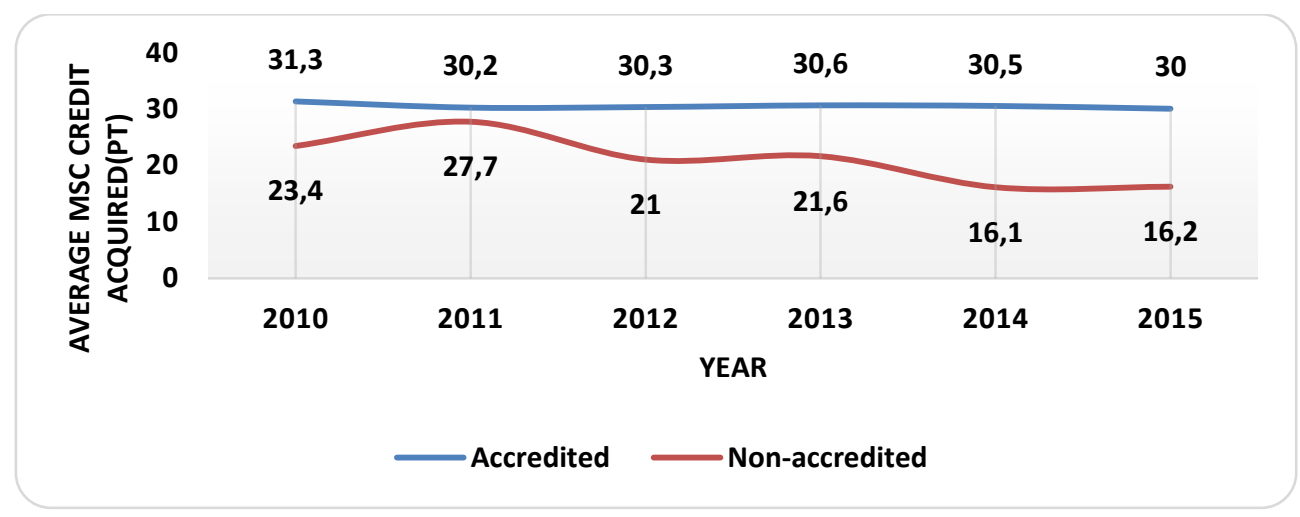

Figure 4. Comparison of fulfillment of MSC credits between accredited and non-accredited graduates by year.

Figure 5 shows the fulfillment of design course credits between accredited and nonaccredited graduates by year. The Department of Materials Engineering at the University of Seoul requires non-accredited students to complete at least six credits in Introductory Design and Capstone Design, which are designated as mandatory courses, and accredited students to earn an additional 9 credits in design courses. Accredited students earned at 
least 15 credits in design courses to meet graduation requirements, whereas non-accredited students earned between 3.4 to 9.1 credits after 2013. The difference between the two groups grew larger over the years.

Design courses are effective in enhancing creativity, teamwork, and communication skills. Past research has shown that students who complete more design courses tend to have a better chance of employment7). The decrease in the fulfillment of credits for design courses among non-accredited graduates after 2013 is likely related to their decline in employment rate.

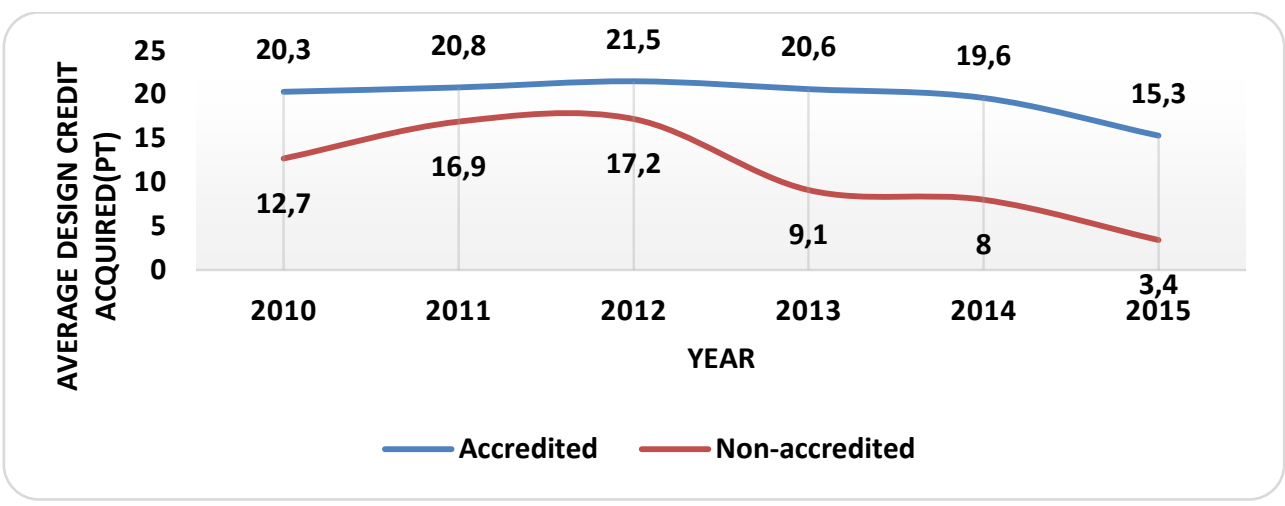

Figure 5. Comparison of fulfillment of credits in design courses between accredited and non-accredited graduates by year.

Figure 6 shows the fulfillment of major course credits between accredited and nonaccredited graduates by year. Both groups must complete at least 60 credits in major courses to successfully graduate. The graph shows that non-accredited students fulfilled the minimum number of credits, while accredited students surpassed the requirement and earned more than 70 credits. This means that non-accredited students took fewer MSC and design courses, and completed other courses that are less helpful in gaining employment in order to meet graduation requirements. 


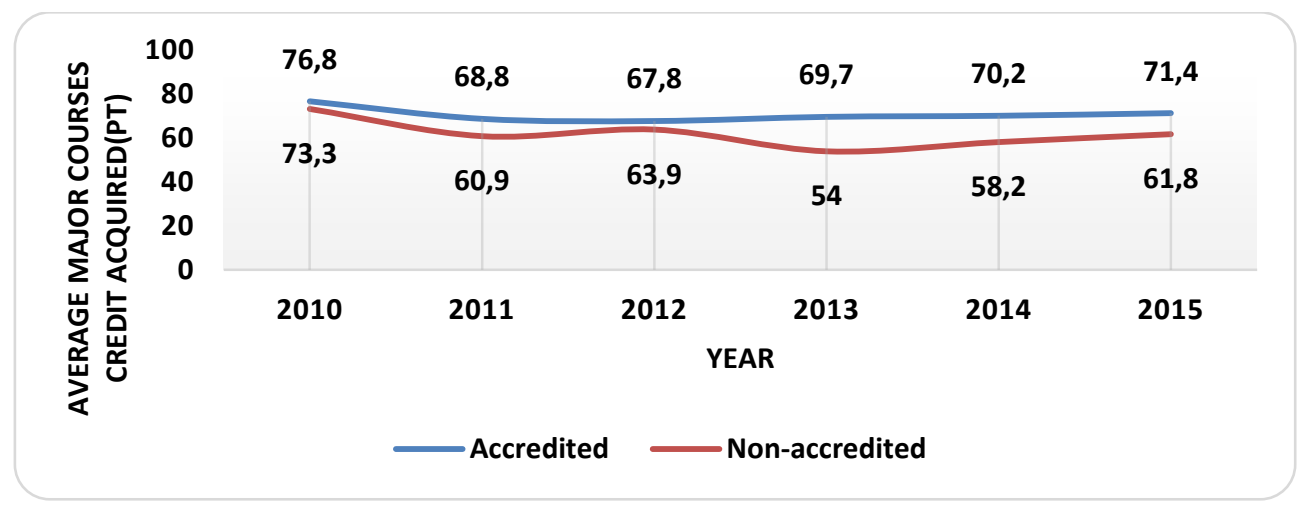

Figure 6. Comparison of fulfillment of credits in major courses between accredited and non-accredited graduates by year.

\section{Conclusion and Discussion}

This study performed a comparative analysis of GPA, employment rate, and completion of credits (MSC, design courses, major courses) between accredited graduates and nonaccredited graduates of the Department of Materials Engineering at the University of Seoul, which has implemented the accredited system for ten years. The following conclusions were derived.

Throughout the research period (2009-2016), accredited graduates had a higher GPA than non-accredited graduates. The employment rate of accredited graduates was also higher, by $5.2-67.5 \%$.

With the implementation of the Engineering Education Accreditation system, the intensive program in materials engineering at the University of Seoul encouraged students to complete more credits in MSC, design, and major courses. Based on past research on the relationship between courses and student competency, such courses are expected to have enhanced their communication skills, teamwork, and creativity. Ultimately, the program can be considered as having produced talented individuals in materials engineering who possess advanced knowledge and skills, thereby improving their employment rate.

The above results demonstrate that the accredited program offered by the Department of Materials Engineering at the University of Seoul has a positive effect on the employment rate of students. 


\section{References}

H. J. Jeon, H. J. Kim, Y. W. Kim. (2013). A Comparative Analysis of Employment Rate between Certified Graduates and Non-certified Graduates by the Engineering Education Accreditation at the University of Seoul (in Korean), Journal of Engineering Education Research, 16(1), 64-74.

J. W. Hwang, H. J. Kim, O. S. Song. (2016). The Relationship between Course Grades and the K-CESA Core Competencies for Engineering Students (in Korean), Journal of Engineering Education Research, 19(4), 35-46.

M. J. Park, S. C. Hong. (2015). Engineering Students' Perceptions of Accredited Engineering Program Performance (in Korean), Journal of Engineering Education Research, 15(4), 57-65.

S. H. Cho, S. Y. Kang. (2012). A Study on the Effects of Accreditation on Curriculum in Engineering Education (in Korean), Journal of Engineering Education Research, 15(4), $58-65$.

S. Y. Kang, S. J. Hon, K. J. Choi, S. H. Park, S. H. Cho. (2013). A Study on the Effects of Engineering Education Accreditation (in Korean), Journal of Engineering Education Research, 18(3), 59-68.

Y. W. Kim, H. J. Kim, N. R. Son. (2014). Effect of Accreditation on Graduate Employment Rates in the Same Field as Their Majors at the University of Seoul, Korean Society for Engineering Education.

\section{Acknowledgments}

This work is financially supported by the Korean Ministry of Trade, Industry and Energy in Korea through the fostering project of the Innovation for Engineering Education. 